\title{
TRANSFERÊNCIA SIMULTÂNEA DE CALOR E MASSA ENTRE O AR E SEMENTES DE SOJA EM LEITO FIXO
}

\author{
G. F. M. V. SOUZA ${ }^{1 *}$, R. F. MIRANDA ${ }^{2}$, F. S. LOBATO ${ }^{1}$, M. A. S. BARROZO ${ }^{1}$ \\ ${ }^{1}$ Universidade Federal de Uberlândia, Faculdade de Engenharia Química \\ ${ }^{2}$ Universidade Federal de Uberlândia, Faculdade de Engenharia Mecânica \\ e-mail: glaucia.souza@gmail.com
}

\section{RESUMO}

O objetivo deste trabalho foi realizar um estudo do processo de secagem de sementes de soja em leito fixo, levando em consideração a heterogeneidade da umidade das sementes e temperatura das sementes e do ar neste tipo de secador. Foi realizada a simulação matemática do processo de secagem utilizando o modelo a duas fases. Através dos experimentos de secagem de sementes de soja em leito fixo e camada espessa, foi possível determinar a umidade das sementes e as temperaturas das sementes e do ar de secagem ao longo do leito, em diferentes posições axiais no decorrer do tempo. Foi constatada a heterogeneidade desse procedimento, neste tipo de secador. Com relação a modelagem, as respostas simuladas comparadas com os valores experimentais mostraram uma boa concordância, com desvios médios de 1,4 a 5,7\%.

\section{INTRODUÇÃO}

A secagem artificial da semente de soja envolve uma série de particularidades. Para sementes de soja recebidas na unidade de beneficiamento com mais de $14,5 \%$ de umidade em base seca (bs), recomenda-se realizar a secagem, até a umidade em torno de 13,5 a $14 \%$ (bs) para um armazenamento seguro sem grandes prejuízos à qualidade fisiológica das sementes (SINNECKER; MACCHIONE E LANFER-MARQUEZ, 2005). Um processo de secagem eficiente é aquele que, além de reduzir o teor de água do produto, aumenta seu potencial de conservação pós-colheita preservando suas características físicas e propriedades tecnológicas (MUJUMDAR, 2006).

A literatura traz relatos sobre alterações na qualidade das sementes durante a secagem, seja em leitos móveis (FELIPE; BARROZO, 2003; BARROZO et al, 2006; LISBOA et al, 2007) ou em leitos fixos (KRZYZANOWSKI; WEST; FRANÇA
NETO, 2006; BARROZO et al, 2005). Os gradientes de temperatura e umidade ocasionam expansão, contração e alterações na densidade e porosidade durante o processo de secagem, desse modo as sementes sofrem mudanças físicas. $\mathrm{O}$ processo de secagem nem sempre aumenta o percentual de sementes quebradas, mas pode provocar fissuras internas ou superficiais, o que torna as sementes mais suscetíveis à quebra durante outras operações (VILLELA, 1991).

Devido ao cuidado exigido em qualquer sistema que envolve mover as sementes, o que pode levar a danos mecânicos, é recomendado o uso de secadores de leito fixo. Neste tipo de secador, a semente permanece estática e o ar de secagem é forçado a passar através do espaço intersticial da massa de sementes. As sementes devem ser secas até uma umidade inferior a 14\% (bs) para um armazenamento seguro sem grandes prejuízos à qualidade fisiológica destas (LACERDA; LISBOA; BARROZO, 2005). 
Os modelos matemáticos para a secagem de grãos encontrados na literatura podem também serem utilizados para sementes. Assim, a conveniente modelagem e simulação computacional dos perfis de temperatura e umidade no secador, uma vez validada por dados experimentais, permite, por exemplo, examinar e interpretar a influência das condições operacionais sobre o processo, sem a necessidade de recorrer a um extensivo conjunto de testes experimentais. Além disto, uma maior compreensão da transferência de calor e massa entre o sólido e o fluido contribui para o projeto e controle de novos secadores, bem como para a otimização de secadores já existentes, assegurando a obtenção de um produto final em condições adequadas de beneficiamento e armazenamento (BARROZO; MURATA; COSTA, 1998).

No entanto, deve-se ressaltar que a experimentação é de suma importância, uma vez que contribui para o desenvolvimento de modelos matemáticos mais realistas e para a verificação da precisão e credibilidade das simulações.

O chamado modelo a duas fases pode ser utilizado para modelar a secagem (grãos ou sementes, e outros materiais) em leitos fixos e móveis. Barrozo, Murata e Costa (1998) analisou a transferência de calor e massa entra o ar e sementes de soja através da simulação utilizando o modelo citado em leitos móveis (concorrente e contracorrente), alcançando bons resultados comparando-se com valores experimentais. Arruda et al (2009) estudou a transferência de calor e massa entre o ar e partículas de fertilizante em secador rotativo convencional e secador rotoaerado, bem como os resultados da simulação com os dados experimentais, obtendo uma boa concordância entre os valores. Este modelo compreende equações de balanço de massa e energia aplicadas às fases, fluida e sólida, e requer equações constitutivas para: o coeficiente de transferência de calor entre estas duas fases; a cinética de secagem; e para o equilíbrio.

O principal objetivo deste estudo foi analisar a transferência de calor e massa durante a secagem de sementes de soja em leito fixo, considerando a heterogeneidade do processo ao longo do leito em função das variáveis de secagem. A validação experimental da metodologia utilizada permite a determinação de condições mais adequadas para a qualidade das sementes após secagem em leito fixo.

\section{MODELO MATEMÁTICO}

Algumas considerações são assumidas para o desenvolvimento do modelo (BROOKER; BAKKER-ARKEMA; HALL, 1974): os escoamentos do fluido tem perfil plano de velocidade; a convecção na superfície do sólido é o mecanismo predominante no processo de troca térmica; a perda de calor é desprezível através das paredes do sistema; a transferência de calor na direção normal ao escoamento é desprezível em relação à transferência de calor nas direções dos escoamentos; leito com propriedades homogêneas; escoamentos unidirecionais do fluido; propriedades físicoquímicas constante ao longo do leito.

$\mathrm{O}$ balanço de energia e de massa é feito através da análise das trocas em um volume diferencial localizado no leito fixo, gerando as Equações 1 a 4 seguintes em conjunto com as condições iniciais e de contorno.

a) Conservação de massa

$\Rightarrow$ Fluido

$\frac{\partial W}{\partial t}=\frac{1}{\varepsilon \rho_{S}}\left(f-G_{f} \frac{\partial W}{\partial \mathrm{y}}\right)$

$\Rightarrow$ Sólido

$\frac{\partial M}{\partial t}=\frac{-f}{(1-\varepsilon)}$ 
b) Conservação de Energia

$\Rightarrow$ Fluido

$\frac{\partial T_{f}}{\partial t}=\frac{-h A\left(T_{f}-T_{s}\right)-G_{f}\left(C p_{f}+W C p_{v}\right) \frac{\partial T_{f}}{\partial t}}{\varepsilon \rho_{f}\left(C p_{f}+W C p v\right)}$

$\Rightarrow$ Sólido

$$
\frac{\partial T_{s}}{\partial t}=\frac{h A\left(T_{f}-T_{s}\right)-f\left(\lambda+C p_{v}\left(T_{f}-T_{s}\right)\right)}{(1-\varepsilon) \rho_{S}\left(C p_{S}+\rho_{S} M C p_{l}\right)}
$$

As condições iniciais e de contorno foram:

$\Rightarrow$ Condições iniciais:

$M=M(\mathrm{y}, 0)=M_{0}$

$T_{s}=T_{s}(\mathrm{y}, 0)=T_{s 0}$

$\Rightarrow$ Condições de contorno:

$W=W(0, \mathrm{t})=W_{0}$

$T_{f}=T_{f}(0, \mathrm{t})=T_{f 0}$

\subsection{Equações constitutivas}

Para prever o teor de umidade de equilíbrio $(M e q)$ de sementes de soja foi utilizada a equação Halsey modificada, (OSBORN et al., 1989), Equação 5, com parâmetros estimados por Barrozo et al (2005).

$M_{e q}=\frac{\left[\left(\frac{-\exp \left(-0,00672 * T_{s}+3,02\right)}{\ln (\mathrm{RH})}\right)^{1 / 1,508}\right]}{100}$

para $M_{e q}$ em bs, $U R$ decimal e $T_{s}$ em ${ }^{\circ} \mathrm{C}$.

Os mesmos autores (BARROZO et al, 2005), obtiveram a equação de cinética de secagem de sementes de soja (Equação 6), a partir de dados de secagem em camada fina.

$M R=\frac{M-M_{e q}}{M_{0}-M_{e q}}=\exp \left(-(K t)^{0,540}\right)$

onde $K=\exp \left(8,61-\left(4558,8 / T_{f}+273,15\right)\right)$, para $t$ em minutos e $T_{f}$ em Kelvin.

A equação da taxa de secagem (Equação 7) é obtida a partir da Equação 6, assim da Equação 7, substituindo na Equação 2 pode ser obtido o valor $\operatorname{de} f$.

$\frac{\partial M}{\partial t}=\frac{-0,54\left(M_{0}-M_{e q}\right) K \exp ^{-(K t)}{ }^{0,54}}{(K t)^{0,46}}$

Com relação ao coeficiente de transferência de calor (h), Equação 8, a correlação utilizada para leito fixo proposta por Wakao, Kaguei e Funazkri (1979) já foi utilizada com sucesso para grãos de soja, sendo utilizada também no presente trabalho.

$\mathrm{Nu}=2+1,1 \operatorname{Pr}^{1 / 3} \operatorname{Re}^{0,6}$

onde: $0,67<\operatorname{Pr}<1$ e $15<\operatorname{Re}<8,5.10^{3}$

Para resolução do modelo proposto foi utilizado o método das linhas, sendo utilizado o software Matlab ${ }^{\circledR}$ para resolver as derivadas temporais.

\section{MATERIAIS E MÉTODOS}

Para os procedimentos experimentais foram utilizadas sementes comerciais de soja da variedade BRS Valiosa, geneticamente modificada, com diâmetro médio de Sauter $\mathrm{dp}=6 \times 10^{-3} \mathrm{~m}$, densidade $\rho=1,19 \times 10^{-3} \mathrm{~kg} \cdot \mathrm{m}^{-3}$, e com o leito apresentando porosidade $\varepsilon=0,37$.

\subsection{Aparato experimental}

A Figura 1 descreve a unidade experimental utilizada. $\mathrm{O}$ sistema era 
constituído por um soprador tipo ventilador radial de 7,5 cv (1), uma válvula para controle de vazão (2), um aquecedor elétrico equipado com um variador de voltagem para ajuste da temperatura do ar de entrada (3), controlador de temperatura (4), um medidor de vazão do tipo anemômetro de fio quente (5), um umidificador de ar para controle da umidade do ar de entrada (6) e o leito fixo composto por uma região cônica para distribuição do ar (7) e pela zona de secagem (8), constituída por uma seção cilíndrica de $0,25 \mathrm{~m}$ de diâmetro por $0,6 \mathrm{~m}$ de altura.

Figura 1- Esquema da unidade experimental

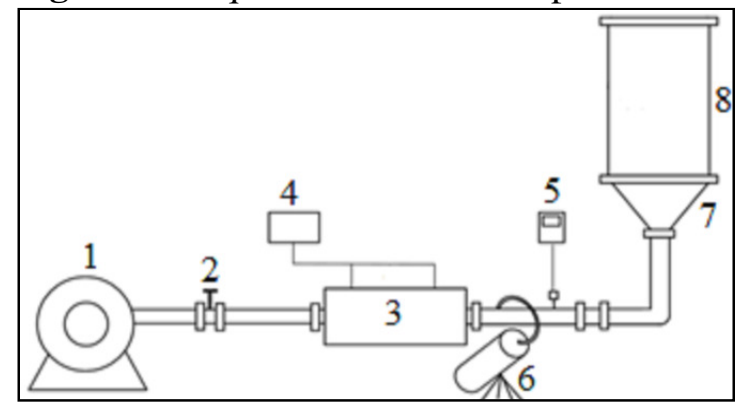

Fonte: SOUZA, 2013

\subsection{Condições operacionais}

As condições experimentais foram determinadas através de um planejamento composto central (BOX; HUNTER; HUNTER, 1978). Foram 16 condições operacionais, considerando três repetições no ponto central. A Tabela 1 mostra os níveis de temperatura $\left(T_{f}\right)$, velocidade superficial $\left(V_{f}\right)$ e umidade relativa (UR) do ar de secagem utilizadas neste trabalho.

Tabela 1 - Níves das condições operacionais

\begin{tabular}{cccc}
\hline Níveis & \multicolumn{3}{c}{ Variáveis } \\
\hline$x$ & $\mathrm{~T}_{f}\left({ }^{\circ} \mathrm{C}\right)$ & $\mathrm{V}_{f}\left(\mathrm{~ms}^{-1}\right)$ & $\mathrm{UR}(\%)$ \\
$-\alpha=-1,41$ & 32,9 & 0,27 & 20,8 \\
-1 & 35,0 & 0,4 & 25,0 \\
0 & 40,0 & 0,7 & 35,0 \\
+1 & 45,0 & 1,0 & 45,0 \\
$+\alpha=1,41$ & 47,0 & 1,12 & 49,1 \\
\hline
\end{tabular}

\subsection{Metodologia experimental}

O sistema foi ajustado para as condições de funcionamento previamente estabelecidas pelo planejamento experimental (Tabela 1) e em seguida, as sementes de soja foram colocados no leito fixo, até atingir uma camada de 0,4 m, iniciando a contagem de tempo do experimento. Temperaturas de bulbo seco e úmido foram obtidas a partir de termopares de cobre-constantan. A velocidade do ar foi medida usando um anemômetro de fio quente. A precisão das medições de temperatura $\left(\mathrm{T}_{f}\right)$, velocidade $\left(\mathrm{V}_{f}\right)$ e o ar de umidade relativa (UR) foram de $\pm 0,3^{\circ} \mathrm{C}$, $\pm 0,05 \mathrm{~ms}^{-1} \mathrm{e} \pm 4 \%$, respectivamente.

A amostragem foi realizada ao longo do leito nas posições axiais: $0,05,0,10,0,20$, 0,30 e $0,40 \mathrm{~m}$. Amostras de sementes foram coletadas após 20, 40, 70, 110, 140 e 180 minutos para a determinação de umidade das sementes. A umidade da semente foi determinada pelo método da estufa a $105 \pm 3$ ${ }^{\circ} \mathrm{C}$ durante $24 \mathrm{~h}$. A umidade inicial das sementes foi de 20,0 $\pm 0,2(\% \mathrm{db})$. As temperaturas da semente e do ar foram medidas em 25, 55, 85, 120, 160 e 180 minutos. Para as medições de temperatura das sementes, as amostras foram imediatamente colocadas em pequenos recipientes isolados termicamente e um termopar de cobreconstantan, instalado no interior de cada recipiente efetuou a medida.

\section{RESULTADOS E DICUSSÃO}

\subsection{Resultados experimentais e simulados}

As Figuras 2 a 4 mostram resultados típicos para os perfis de umidade da soja (bs), temperaturas do ar de secagem e temperatura das sementes $\left({ }^{\circ} \mathrm{C}\right)$, durante o tempo, em diferentes posições axiais do leito.

Nestas figuras são apresentados os dados experimentais e as respectivas respostas simuladas.

O desvio médio entre os resultados experimentais e simuladas para a umidade das 
sementes no final do processo foi de $6 \%$. Este desvio é ligeiramente maior do que a incerteza de medida.

Figura 2 - Perfis de umidade da soja (bs) experimentais e simulados no decorrer do tempo para as posições na direção axial do leito 0,$05 ; 0,10 ; 0,20 ; 0,30$ e $0,40 \mathrm{~m}$, para os experimentos 2 (A) e 12 (B), respectivamente.
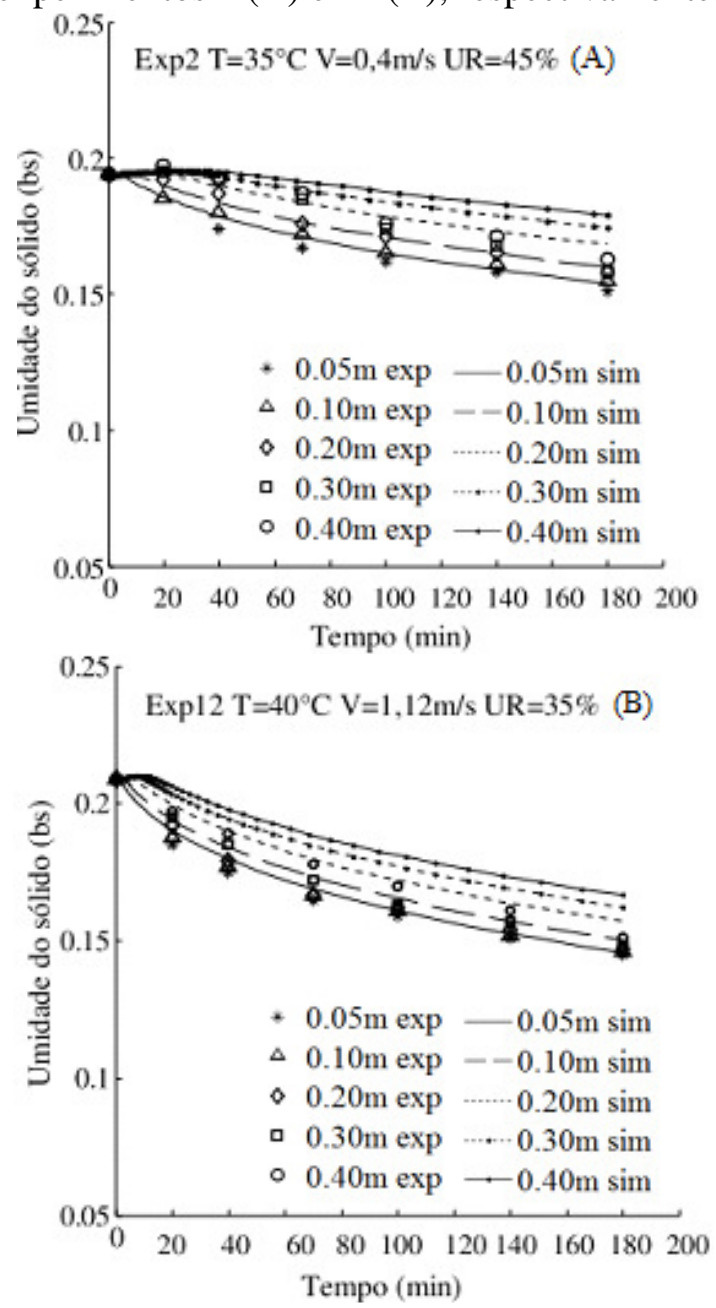

Pode ser visto na Figura 3 que existe uma concordância muito boa entre os valores simulados e experimentais da temperatura do ar ao longo do tempo nas diferentes posições axiais de cama. $\mathrm{O}$ desvio médio entre esses valores ficou em torno de $2,8 \%$.

Esse desvio ficou muito próximo da incerteza da medida experimental, o que mostra uma ótima capacidade do modelo em prever a distribuição dessa variável ao longo do leito.

Figura 3 - Perfis de temperatura do ar de secagem $\left({ }^{\circ} \mathrm{C}\right)$ experimentais e simulados no decorrer do tempo para as posições na direção axial do leito 0,$05 ; 0,10 ; 0,20 ; 0,30$ e $0,40 \mathrm{~m}$, para os experimentos 4 (A) e 5 (B), respectivamente.
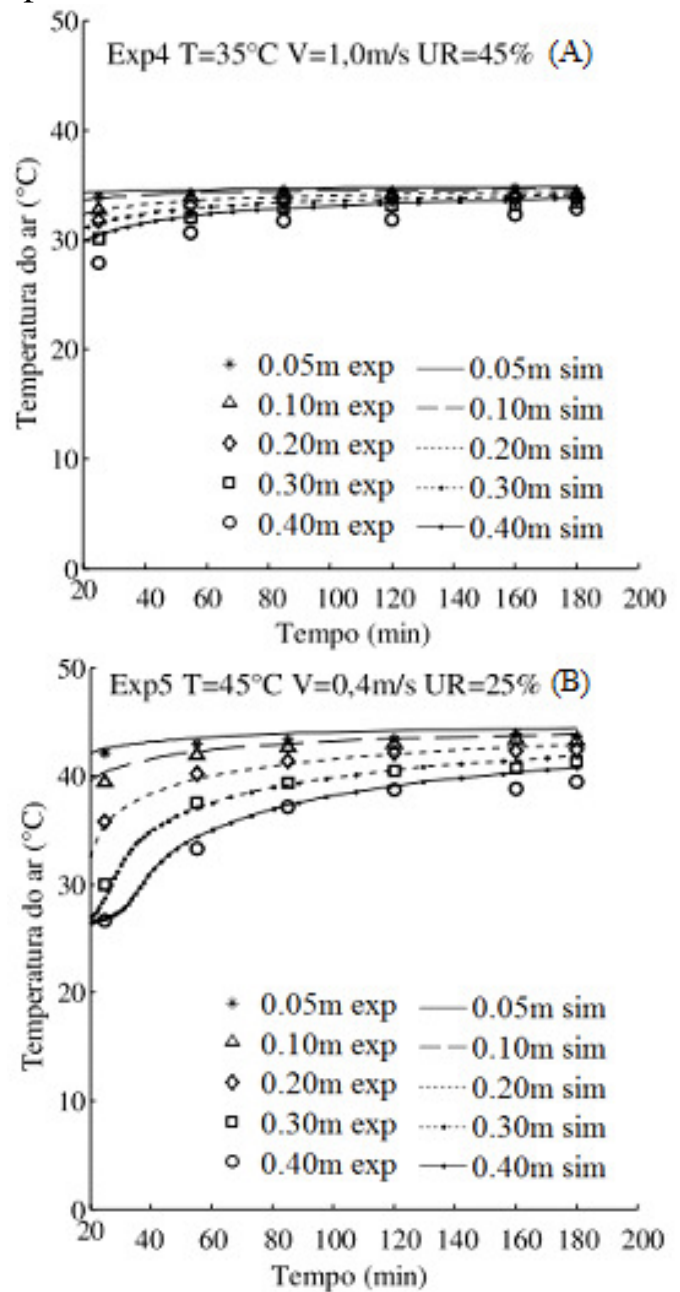

Já o desvio entre os valores simulados e os experimentais para a temperatura das sementes (Figura 4) foi superior às demais variáveis, em torno de $8 \%$. Isso é devido provavelmente a menor precisão da medida experimental da temperatura das sementes, uma vez que no momento da coleta até a 
estabilização para realização da leitura pode ocorrer transferência de calor diminuindo assim a temperatura das sementes.

Figura 4 - Perfis de temperatura das sementes de soja $\left({ }^{\circ} \mathrm{C}\right)$ experimentais e simulados no decorrer do tempo para as posições na direção axial do leito 0,$05 ; 0,10 ; 0,20 ; 0,30$ e $0,40 \mathrm{~m}$, para os experimentos 5 (A) e 16 (B), respectivamente.
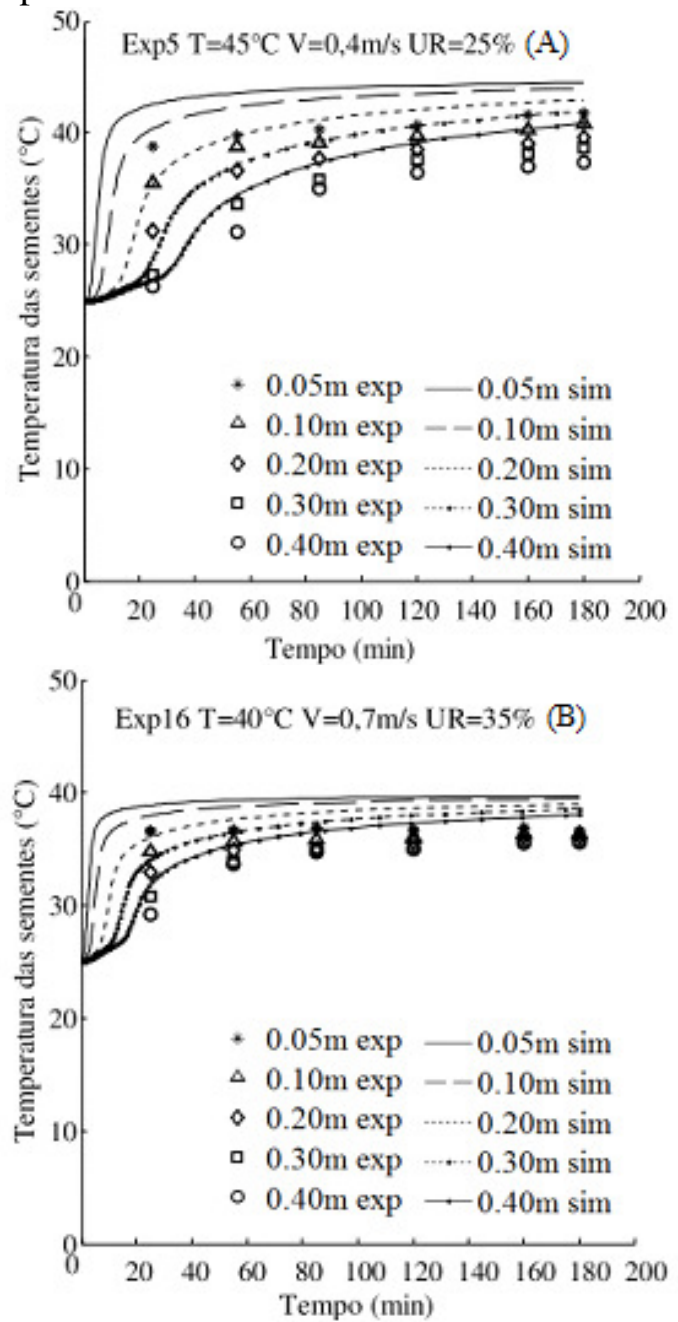

Observa-se que, de um modo geral, o modelo a duas fases forneceu bons resultados para representar a transferência de calor e massa do processo de secagem de sementes de soja em leito fixo.
Vale ressaltar que não foram feitos ajustes de parâmetros, mas uma comparação direta dos dados experimentais com aqueles previstos pela simulação, com os parâmetros originais das equações constitutivas. Esta estratégia permite uma análise mais realista da previsibilidade do modelo.

Um comportamento similar ao obtidos nestes resultados foi observado também nas demais situações estudadas.

\subsection{Heterogeneidade do processo}

As Tabelas 2 e 3 mostram a taxa de secagem e a umidade das sementes de soja em posições axiais de $0,05 \mathrm{~m}$ (perto da entrada de ar) e $0,40 \mathrm{~m}$ (topo da cama) obtidos após a secagem, em todas as condições operacionais.

Tabela 2 - Taxas de secagem em pontos percentuais por hora $\left(\mathrm{pp} \mathrm{h}^{-1}\right)$ de sementes de soja secas nas diferentes posições axiais do leito fixo após 180 minutos.

\begin{tabular}{|c|c|c|c|}
\hline & $\begin{array}{c}\text { Condições } \\
\text { operacionais } \\
\left(T_{f} / V_{f} / R H_{f}\right)\end{array}$ & $\begin{array}{r}\mathrm{Ta} \\
\text { secage } \\
\text { Posiç }\end{array}$ & $\begin{array}{l}\text { de } \\
\left(p p \cdot h^{-1}\right) \\
\text { axial }\end{array}$ \\
\hline & & $0,05 \mathrm{~m}$ & $0,40 \mathrm{~m}$ \\
\hline 1 & $35^{\circ} \mathrm{C} / 0,4 \mathrm{~ms}^{-1} / 25 \%$ & 2,06 & 1,75 \\
\hline 2 & $35^{\circ} \mathrm{C} / 0,4 \mathrm{~ms}^{-1} / 45 \%$ & 1,55 & 1,17 \\
\hline 3 & $35^{\circ} \mathrm{C} / 1,0 \mathrm{~ms}^{-1} / 25 \%$ & 2,16 & 1,84 \\
\hline 4 & $35^{\circ} \mathrm{C} / 1,0 \mathrm{~ms}^{-1} / 45 \%$ & 1,73 & 1,37 \\
\hline 5 & $45^{\circ} \mathrm{C} / 0,4 \mathrm{~ms}^{-1} / 25 \%$ & 2,30 & 2,00 \\
\hline 6 & $45^{\circ} \mathrm{C} / 0,4 \mathrm{~ms}^{-1} / 45 \%$ & 1,93 & 1,68 \\
\hline 7 & $45^{\circ} \mathrm{C} / 1,0 \mathrm{~ms}^{-1} / 25 \%$ & 2,39 & 2,06 \\
\hline 8 & $45^{\circ} \mathrm{C} / 1,0 \mathrm{~ms}^{-1} / 40 \%$ & 2,10 & 1,86 \\
\hline 9 & $32,9^{\circ} \mathrm{C} / 0,7 \mathrm{~ms}^{-1} / 35 \%$ & 1,83 & 1,50 \\
\hline 10 & $47^{\circ} \mathrm{C} / 0,7 \mathrm{~ms}^{-1} / 35 \%$ & 2,31 & 2,01 \\
\hline 11 & $40^{\circ} \mathrm{C}-0,27 \mathrm{~ms}^{-1} / 35 \%$ & 2,10 & 1,30 \\
\hline 12 & $40^{\circ} \mathrm{C} / 1,12 \mathrm{~s}^{-1} / 35 \%$ & 2,13 & 1,94 \\
\hline 13 & $40^{\circ} \mathrm{C} / 0,7 \mathrm{~m} \mathrm{~s}^{-1} / 20,8 \%$ & 2,35 & 2,06 \\
\hline 14 & $40^{\circ} \mathrm{C} / 0,7 \mathrm{~m} \mathrm{~s}^{-1} / 49,1 \%$ & 1,64 & 1,15 \\
\hline 15 & $40^{\circ} \mathrm{C} / 0,7 \mathrm{~m} \mathrm{~s}^{-1} / 35 \%$ & 1,84 & 1,57 \\
\hline 16 & $40^{\circ} \mathrm{C} / 0,7 \mathrm{~m} \mathrm{~s}^{-1} / 35 \%$ & 1,85 & 1,59 \\
\hline
\end{tabular}

Uma variação expressiva nesta variável pode ser observada entre as diferentes posições axiais do leito, em todos os 
experimentos. Assim, uma importante diminuição na taxa de secagem é observada comparando-se os resultados da posição axial de $0,05 \mathrm{~m}$, com $0,4 \mathrm{~m}, \quad$ o que, consequentemente, leva a heterogeneidade do produto final.

As diferenças entre as posições $0,05 \mathrm{e}$ $0,40 \mathrm{~m}$ foram maiores do que 0,30 $\pm 0,05$ $\mathrm{pp} \mathrm{h}^{-1}$ para a maioria dos experimentos $(1,3$, $5,6,7,9,10,13,15$ e 16). As maiores diferenças foram de 0,80 e $0,49 \mathrm{pp} \mathrm{h}^{-1}$ para o experimento 11 e para o experimento 14, respectivamente. Nota-se que as maiores diferenças foram observadas nas condições de baixa velocidade do ar (experimento 11) e sob elevada umidade relativa do ar (experimento 14). A menor diferença entre as velocidades de secagem em diferentes posições axiais do leito foi de $0,19 \mathrm{pp} \mathrm{h}^{-1}$, obtida com a maior velocidade do ar de secagem $\left(1,12 \mathrm{~m} \mathrm{~s}^{-1}\right.$, experimento 12). Assim, as condições que favorecem uma maior saturação do leito são aquelas que também promovem uma redução na taxa de secagem ao longo do leito.

As umidades finais obtidas nos experimentos para as sementes de soja após secagem em leito fixo nas posições axiais 0,05 e 0,40 m estão descritas na Tabela 3.

Em apenas quatro experimentos (exp. 5, 7, 13 e 16) as sementes alcançaram a umidade final desejada, i.e. abaixo de $14 \%$ (bs), nas diferentes posições axiais do leito. Dentre estes quatro experimentos o experimento 16 é aquele em que as condições são menos desfavoráveis para a qualidade das sementes $\left(40^{\circ} \mathrm{C} ; 0,7 \mathrm{~m} \mathrm{~s}^{-1}\right.$ e $35 \%$ de UR).

Nota-se novamente para todos os experimentos que houve variação da umidade final das sementes, nas diferentes posições axiais do leito. Observa-se que as sementes da camada superior, $0,40 \mathrm{~m}$, que estão em contato com o ar mais frio e mais úmido, apresentaram maiores valores de umidade, evidenciando assim a heterogeneidade do produto.
Tabela 3 - Umidade final das sementes de soja secas nas diferentes posições axiais do leito fixo, após 180 minutos.

\begin{tabular}{cccc}
\hline & \multirow{2}{*}{$\begin{array}{c}\text { Condições } \\
\text { operacionais }\end{array}$} & \multicolumn{2}{c}{$\begin{array}{c}\text { Umidade final nas } \\
\text { posições do leito }\end{array}$} \\
\cline { 3 - 4 } & $\left(T_{f} / V_{f} / R H_{f}\right)$ & $0.05 \mathrm{~m}$ & $0.40 \mathrm{~m}$ \\
\hline 1 & $35^{\circ} \mathrm{C} / 0,4 \mathrm{~ms}^{-1} / 25 \%$ & 14,2 & 15,2 \\
2 & $35^{\circ} \mathrm{C} / 0,4 \mathrm{~ms}^{-1} / 45 \%$ & 15,1 & 16,3 \\
3 & $35^{\circ} \mathrm{C} / 1,0 \mathrm{~ms}^{-1} / 25 \%$ & 13,9 & 14,9 \\
4 & $35^{\circ} \mathrm{C} / 1,0 \mathrm{~ms}^{-1} / 45 \%$ & 15,3 & 16,4 \\
5 & $45^{\circ} \mathrm{C} / 0,4 \mathrm{~ms}^{-1} / 25 \%$ & 13,1 & 14,0 \\
6 & $45^{\circ} \mathrm{C} / 0,4 \mathrm{~ms}^{-1} / 45 \%$ & 14,1 & 14,9 \\
7 & $45^{\circ} \mathrm{C} / 1,0 \mathrm{~ms}^{-1} / 25 \%$ & 12,6 & 13,6 \\
8 & $45^{\circ} \mathrm{C} / 1,0 \mathrm{~ms}^{-1} / 40 \%$ & 13,7 & 14,4 \\
9 & $32,9^{\circ} \mathrm{C} / 0,7 \mathrm{~ms}^{-1} / 35 \%$ & 14,4 & 15,3 \\
10 & $47^{\circ} \mathrm{C} / 0,7 \mathrm{~ms}^{-1} / 35 \%$ & 13,7 & 14,6 \\
11 & $40^{\circ} \mathrm{C}-0,27 \mathrm{~ms}^{-1} / 35 \%$ & 14,8 & 17,2 \\
12 & $40^{\circ} \mathrm{C} / 1,12 \mathrm{~s}^{-1} / 35 \%$ & 14,5 & 15,1 \\
13 & $40^{\circ} \mathrm{C} / 0,7 \mathrm{~m} \mathrm{~s}^{-1} / 20,8 \%$ & 13,0 & 13,9 \\
14 & $40^{\circ} \mathrm{C} / 0,7 \mathrm{~m} \mathrm{~s}^{-1} / 49,1 \%$ & 15,3 & 16,7 \\
15 & $40^{\circ} \mathrm{C} / 0,7 \mathrm{~m} \mathrm{~s}^{-1} / 35 \%$ & 13,7 & 14,5 \\
16 & $40^{\circ} \mathrm{C} / 0,7 \mathrm{~m} \mathrm{~s}^{-1} / 35 \%$ & 13,7 & 14,3 \\
\hline
\end{tabular}

As maiores heterogeneidades e homogeneidades encontradas são mostradas nas Figuras 5 e 6, para a umidade (A) e para a temperatura (B) das sementes, respectivamente. Pode ser visto nestes resultados que, heterogeneidades mais elevadas foram obtidas com menores velocidades do ar de secagem (Figuras 5A e 5B).

Verifica-se que grandes diferenças na umidade e temperatura das sementes também podem conduzir a um produto final com diferentes níveis de qualidade (SOUZA, 2013).

Um problema importante na secagem de sementes de soja em altas temperaturas é o aparecimento de fissuras no revestimento (tegumento) da semente. Esta condição torna os grãos suscetíveis ao ataque microbiano no armazenamento, e também reduz o potencial de germinação (KRZYZANOWSKI; WEST; FRANÇA NETO, 2006). 
Figura 5 - Umidade (A) e temperatura (B) das sementes soja, no tempo, ao longo das posições axiais do leito fixo $(0,05,0,10,0,20$, 0,30 e $0,40 \mathrm{~m}$ ) para o experimento 11 .
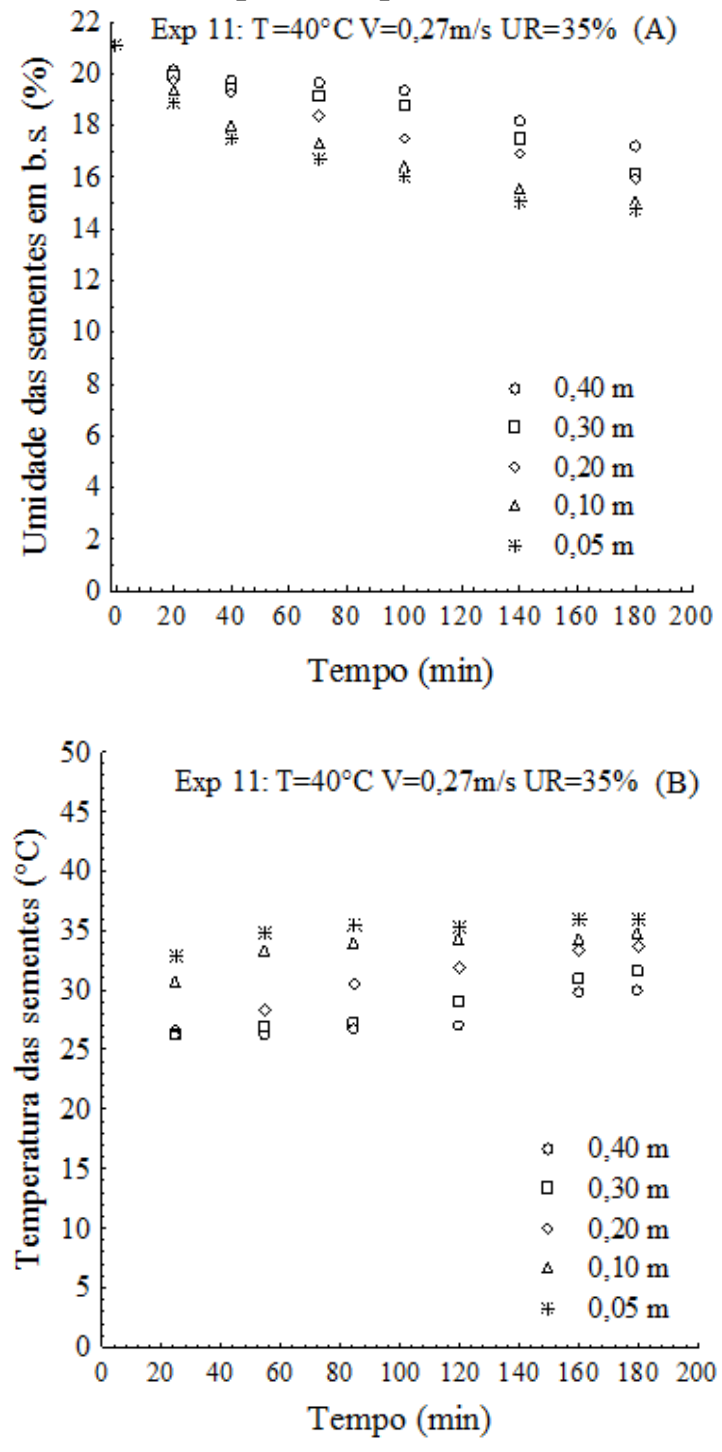

Sementes com uma umidade muito baixa, também torna o tegumento mais propenso a rachaduras, enquanto umidade alta das sementes pode resultar em manchas negras que reduz a germinação pela deterioração acelerada (BARROZO et al, 2006). Dependendo das condições de secagem, o tegumento das sementes torna-se mais "plástico" do que "elástico".
Figura 6 - Umidade (A) e temperatura (B) das sementes soja, no tempo, ao longo das posições axiais do leito fixo $(0,05,0,10,0,20$, 0,30 e $0,40 \mathrm{~m}$ ) para o experimento 12 .
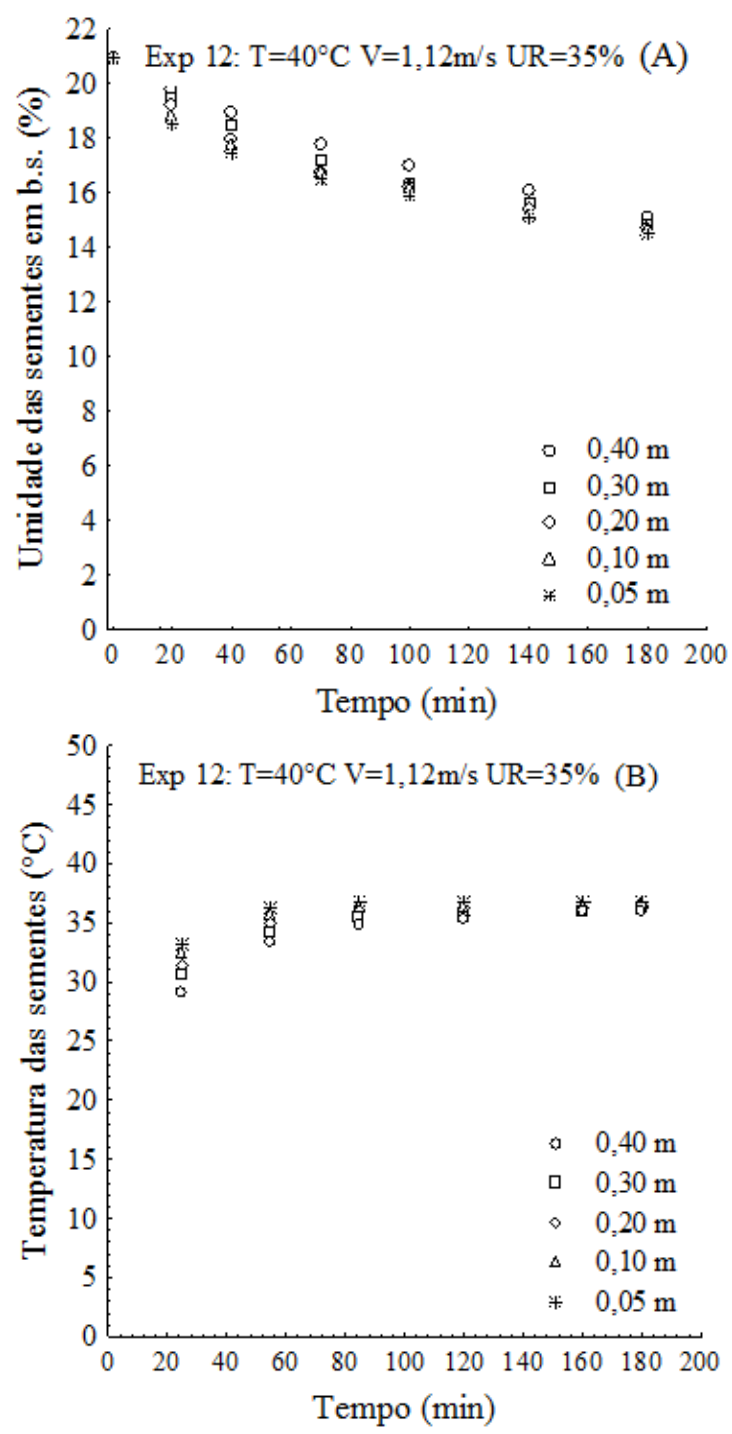

Os cotilédones envolvidos em proteínas têm alta afinidade para absorção de umidade e se expande e se contrai drasticamente, colocando uma certa pressão sobre o revestimento das sementes, que se estende e se enfraquece. Quando os cotilédones secam e encolhem, o tegumento das sementes também encolhe, tornando-se mais propensas a danos. Assim, a previsão das condições finais 
dos produtos por meio de simulação, utilizando um modelo adequado, é essencial para assegurar a obtenção de sementes com boa qualidade, após o processo de secagem.

\section{CONCLUSÕES}

Os resultados do presente estudo mostram que o modelo a duas fases, com um conjunto adequado de equações constitutivas, previu com sucesso o processo de secagem de sementes de soja em camada espessa em um secador de leito fixo. Os resultados simulados obtiveram uma boa concordância com os dados experimentais.

A taxa de perda de umidade das sementes num secador de leito fixo não é uniforme. Existem diferenças expressivas de umidade, de temperatura do ar e das sementes na direção axial, sendo que, como esperado, as menores umidades e maiores temperaturas do ar e das sementes foram alcançadas nas posições mais próximas da entrada do ar no leito.

O modelo previu com sucesso a heterogeneidade das variáveis de secagem ao longo do leito. Uma boa previsão das condições após secagem por simulação, utilizando um modelo adequado, é essencial para garantir a qualidade das sementes.

\section{NOMENCLATURA}

A área interfacial de transferência por unidade de volume do leito, $\left[\mathrm{m}^{-1}\right]$

$C_{p} \quad$ calor específico, $\left[\mathrm{J} . \mathrm{kg}^{-1} \cdot{ }^{\circ} \mathrm{C}^{-1}\right]$

$\mathrm{db}$ base seca, [decimal]

dp diâmetro médio de Sauter da partícula, [m]

$f$ taxa de secagem por unidade de volume do leito, $\left[\mathrm{kg} \mathrm{m}^{-3} \mathrm{~s}^{-1}\right]$

$G \quad$ vazão mássica, $\left[\mathrm{kg} \mathrm{m}^{-2} \mathrm{~s}^{-1}\right.$ ]

$h$ coeficiente de transferência de calor, $\left[\mathrm{kg} \mathrm{K}^{-1} \mathrm{~s}^{-3}\right]$

$h A$ coeficiente volumétrico de transferência de calor sólido-fluido,

\author{
$\left[\mathrm{J} \cdot \mathrm{m}^{-3} \cdot \mathrm{s}^{-1} \cdot{ }^{\circ} \mathrm{C}^{-1}\right]$ \\ $K \quad$ constante de secagem, $\left[\mathrm{kg} \mathrm{m}^{2} \mathrm{~s}^{-1}\right.$ ] \\ $M \quad$ Umidade do sólido (massa de água por \\ massa de sólido seco), [-] \\ $M R \quad$ adimensional de umidade, [-] \\ $\mathrm{Nu}$ número de Nusselt, [-] \\ $\mathrm{pp} \mathrm{h}^{-1}$ pontos percentuais por hora, [-] \\ Pr número de Prandt, [-] \\ Re número de Reynolds, [-] \\ UR umidade relativa do ar, [-] \\ $T$ temperatura, $\left[{ }^{\circ} \mathrm{C}\right]$ \\ $t$ tempo, [s] \\ $V \quad$ velocidade superficial, $\left[\mathrm{m} \mathrm{s}^{-1}\right]$ \\ $y$ Coordenada da direção de escoamento \\ do fluido, [m] \\ $W \quad$ umidade absoluta do ar ( $\mathrm{kg}$ de água \\ por kg de ar seco), [-]
}

Letras gregas

$\varepsilon$ porosidade, [-]

$\lambda$ calor latente de vaporização, $\left[\mathrm{J} \mathrm{kg}^{-1}\right]$

$\rho \quad$ densidade, $\left[\mathrm{kg} \mathrm{m}^{-3}\right]$

Subscritos

$\begin{array}{ll}e q & \text { equilíbrio } \\ f & \text { fluido } \\ l & \text { liquido } \\ 0 & \text { condições de entrada } \\ s & \text { solido } \\ v & \text { vapor }\end{array}$

\section{REFERENCIAS}

ARRUDA, E. B. ; LOBATO, F. S.; ASSIS, A. J.; BARROZO, M. A. S. Modeling of fertilizer drying in roto-aerated and conventional rotary dryers. Drying Technology, v.27, p.1192-1198, 2009.

BARROZO, M. A. S.; MURATA, V. V.; COSTA, S. M. The drying of soybean seeds in countercurrent and concurrent moving bed dryers. Drying Technology, v.16, p.20332047, 1998.

BARROZO, M. A. S.; FREIRE, F. B.; SARTORI, D. J. M.; FREIRE, J. T. Study of 
the drying kinetics in thin layer: fixed and moving bed. Drying Technology, v.23, p.1451-1464, 2005.

BARROZO, M. A. S.; FELIPE, C. A. S.; SARTORI, D. J. M.; FREIRE, J. T. Quality of soybean seeds undergoing moving bed drying: countercurrent and crosscurrent flows. Drying Technology, v.24, p.415-422, 2006.

BOX, M. J.; HUNTER, W. G.; HUNTER, J. S. Statistics for experimenters, an introduction to design, data analysis, and model building. New York, John Wiley and Sons, 1978.

BROOKER, D. B.; BAKKER-ARKEMA, F. $\mathrm{W}$;; HALL, C. W. Drying cereal grains. Connecticut, Westport, AVI Book, 1974.

FELIPE, C. A. S.; BARROZO, M. A. S. Drying of soybean seeds in a concurrent moving bed: heat and mass transfer and quality analysis. Drying Technology, v.21, p.439-456, 2003.

KRZYZANOWSKI, F.C.; WEST, S.H.; FRANÇA NETO, J. B. Drying soybean seed using air ambient temperature at low relative humidity. Revista Brasileira de Sementes, v.28, p.77-83, 2006.

LACERDA, A. F.; LISBOA, M. H.; BARROZO, M. A. S. Heat and mass transfer in a contercurrent moving bed dryer. Applied Thermal Engineering, v.25, p.2641-2652, 2005.

LISBOA, M. H.; VITORINO, D. S.; DELAIBA, W. B.; FINZER, J. R. D.; BARROZO, M. A. S. A study of particle motion in rotary dryer. Brazilian Journal Chemical Engineering, v.24, p.265-374, 2007.

MUJUMDAR, A. S. Some recent developments in drying technologies appropriate for postharvest processing. International Journal of Postharvest Technology and Innovation, v.1, p.76-92, 2006.
OSBORN, G. S.; WHITE, G. M.; SULAIMAN, A. H.; WELTON, L. R. Predicting equilibrium moisture proportions of soybeans. Transaction of the ASAE, v.32, p.2109-2113, 1989.

SINNECKER, P.; BRAGA, N.; MACCHIONE, E. L. A.; LANFERMARQUEZ, U. M. Mechanism of soybean (Glycine max L. Merrill) degreening related to maturity stage and postharvest drying temperature. Postharvest Biology

Technology, v.38, p.269-279, 2005.

SOUZA, G. F. M. V. Secagem de sementes de soja em leito fixo: equilíbrio e cinética da sílica gel para controle de umidade, modelagem do processo e análise da qualidade das sementes. 2013. $157 \mathrm{fl}$. Tese. (Doutorado em Engenharia Mecânica) Universidade Federal de Uberlândia, Uberlândia, 2013.

SRIVASTAVA, V. K.; JOHN, J. Deep bed grain drying modeling. Energy Conversion and Management, v.43, p.16891708, 2002.

VILLELA, F. A. Efeitos da secagem intermitente sobre a qualidade de sementes de milho. 1991. 104 fl. Tese (Doutorado e Produção Vegetal) - Escola Superior de Agricultura "Luiz de Queiroz", Piracicaba, 1991.

WAKAO, N.; KAGUEI, S.; FUNAZKRI, T. Effect of fluid dispersion coefficients on particle-to-fluid heat transfer coefficients in packed beds: Correlation of Nusselt number. Chemical Engineering Science, v.34, p.325336, 1979.

\section{AGRADECIMENTOS}

Os autores agradecem os apoios financeiro do $\mathrm{CNPq}$ e Capes, e estrutural da Universidade Federal de Uberlândia. 